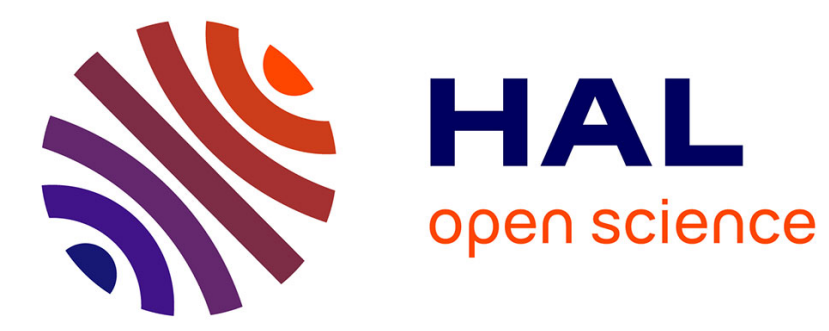

\title{
Structural relaxation of glassy selenium under $\gamma$ irradiation
}

\author{
R. Calemczuk, E. Bonjour
}

\section{To cite this version:}

R. Calemczuk, E. Bonjour. Structural relaxation of glassy selenium under $\gamma$ irradiation. Journal de Physique Lettres, 1981, 42 (22), pp.501-502. 10.1051/jphyslet:019810042022050100 . jpa-00231986

\section{HAL Id: jpa-00231986 https://hal.science/jpa-00231986}

Submitted on 1 Jan 1981

HAL is a multi-disciplinary open access archive for the deposit and dissemination of scientific research documents, whether they are published or not. The documents may come from teaching and research institutions in France or abroad, or from public or private research centers.
L'archive ouverte pluridisciplinaire HAL, est destinée au dépôt et à la diffusion de documents scientifiques de niveau recherche, publiés ou non, émanant des établissements d'enseignement et de recherche français ou étrangers, des laboratoires publics ou privés. 


\title{
Structural relaxation of glassy selenium under $\gamma$ irradiation $\left({ }^{*}\right)$
}

\author{
R. Calemczuk and E. Bonjour \\ Centre d'Etudes Nucléaires, SBT/L.C.P., 85 X, 38041 Grenoble Cedex, France
}

(Reçu le 3 juillet 1981, accepté le 2 octobre 1981)

\begin{abstract}
Résumé. - L'effet du rayonnement $\gamma$ sur la relaxation structurale du sélénium vitreux, au voisinage de la transition vitreuse, a été étudié par dilatométrie. On montre que sous irradiation l'échelle de temps de l'évolution est diminuée par un facteur de l'ordre de 10.
\end{abstract}

Abstract. - The effect of $\gamma$-rays on the structural relaxation of glassy selenium near the glass transition has been studied by dilatometry. We show that under irradiation the evolution time scale shifts about one decade.

1. Introduction. - The temperature $T_{\mathrm{g}}$ of the glass transition is the lowest temperature at which a supercooled liquid is in thermodynamic equilibrium. At lower temperatures the characteristic times of structural evolution are so long that the system is frozen in a glassy state out of equilibrium. The different transport coefficients measured at temperatures higher than $T_{\mathrm{g}}$ show an unusual, simple and general behaviour. The viscosity, dielectric relaxation time and quantities related to the structural mobility seem to diverge at a non-vanishing temperature $T_{0}$, as $\mathrm{e}^{A /\left(T-T_{0}\right)}$ $[1,2] . T_{0}$ lies some tens of degrees below $T_{\mathrm{g}}$. Many attempts have been made to explain this behaviour [3-5], but it still remains an open question [6, 7]. In particular, the nature of the low entropy states near $T_{0}$ is unknown. These states were until now experimentally unattainable. In a recent paper [8], we showed through calorimetric measurements that the structural mobility of bulk glassy selenium is increased by irradiating the sample with gamma rays. This effect allows the system to reach its equilibrium state at temperatures lower than $T_{\mathrm{g}}$.

In order to obtain more detailed information, we have developed a dilatometric method which allows continuous measurements in situ. In this communication we present our results of the effects of $\gamma$ irradiation

(*) Cet article a été présenté au Congrès de la Société Française de Physique (Clermont-Ferrand, juillet 1981) dans le cadre du Colloque "Verres et Amorphes".

This article was presented at the Meeting of the French Physical Society (Clermont-Ferrand, July 1981) at the Symposium on "Glass and Amorphous Materials ". on the evolution of the sample length towards thermodynamic equilibrium.

To make possible the comparison of evolutions with and without irradiation, measurements were performed in a temperature range so that the time evolution scale without irradiation was not longer than a few days. This range corresponds to temperatures in the neighbourhood of $T_{\mathrm{g}}$.

The experimental procedure is described in section 2, and the results are presented and discussed in section 3 .

2. Experimental. - The dilatometric studies have been performed by measuring the variation of the sample length using a capacitive dilatometer.

The sample, a cylinder of $10 \mathrm{~mm}$ length and $10 \mathrm{~mm}$ diameter, was made by melting the material as received (Se $99.999 \%$ from Material Research Co.) in a Pyrex tube and subsequently quenching in water.

The dilatometer, constructed in our laboratory, has been described elsewhere [9]. It allows us to detect changes in the linear dimensions of the sample $\Delta l / l$ of the order of $10^{-6}$. The temperature is controlled by a proportional-integral regulator driving a Peltier device. The accuracy of the isotherms $\Delta l / l$ versus time is limited by the temperature stability which is better than $\pm 0.1 \mathrm{~K}$. The measurements are limited at high temperatures by deformations of the sample due to creep. Even at lower temperatures where this effect is very small, it is still important if we compare it to the length variations in the tail of the relaxation curves. We subtracted a straight base line from the measured length variations to correct this effect.

Experiments under $\gamma$ irradiation were performed using a cobalt source which supplies about $1.2 \times 10^{6} \mathrm{rad} . / \mathrm{h}$. 
3. Results and discussion. - Relaxation measurements were made during the approach to thermodynamic equilibrium at different temperatures $T$. The initial states were always equilibrium states obtained at different temperatures $T_{\mathrm{i}}$. For $T_{\mathrm{i}}-T$ positive (negative) the observed evolution is a dilatation (contraction). We first performed a set of measurements " in the dark", then the same measurements were taken under $\gamma$ irradiation, and we verified the absence of any irreversible effect on the material by repeating the " in the dark » experiment. The $\Delta l / l$ versus time isotherms, for $T=298 \mathrm{~K}$ and $T_{\mathrm{i}}=303 \mathrm{~K}$ are shown in figure 1 . This result displays the dramatic effect produced by $\gamma$ radiation. Under irradiation, the time necessary to reach the equilibrium (10 hours) is 25 times smaller than in the dark (10 days).

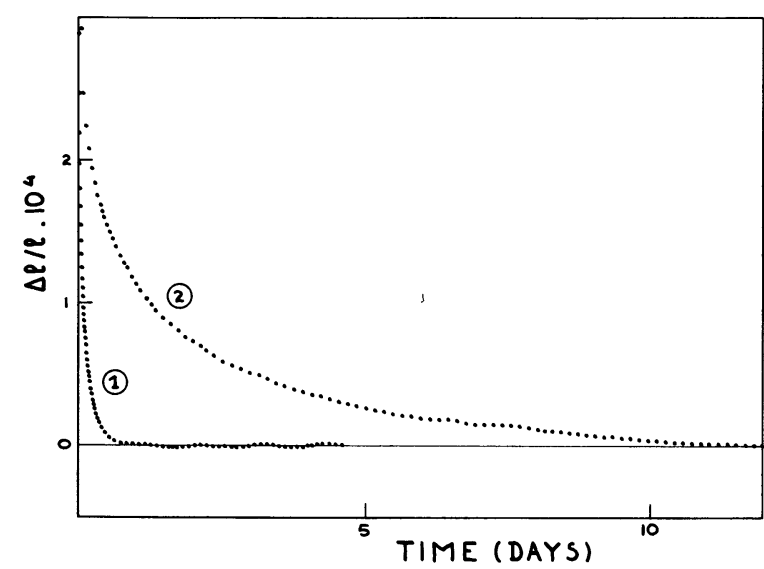

Fig. 1. - Time evolution of the sample length observed at $T=298 \mathrm{~K}$ after quenching from equilibrium at $T_{\mathrm{i}}=303 \mathrm{~K}$. (1) under $\gamma$ irradiation; (2) " in the dark ».

In our previous calorimetric study [8], we concluded that the gamma irradiation does not modify the equilibrium state itself. The present dilatometric measurements confirm this conclusion; when a sample at equilibrium is irradiated, there is no sensible length variation.

To discuss the results, let us define $\tau$, the instantaneous effective relaxation time, by

$$
\tau=-\frac{\delta}{(\mathrm{d} \delta / \mathrm{d} t)} ; \quad \delta=\frac{\Delta l}{l} .
$$

In the case of an exponential behaviour with a single relaxation time, this quantity would be constant. In

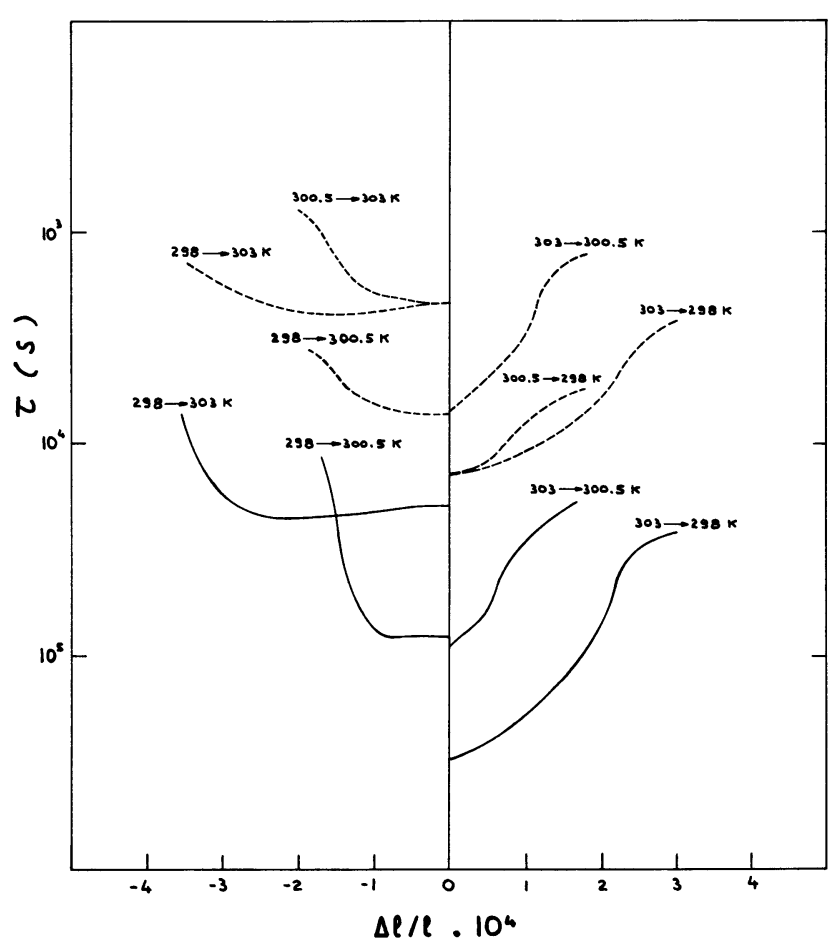

Fig. 2. - Plots of $\log (\tau)$ vs. $\Delta l / l$ (Eq. (1)). The numbers near each curve correspond to the initial equilibrium temperature $T_{\mathrm{i}}$ and the observation temperature $T,\left(T_{\mathrm{i}} \rightarrow T\right)$. Dashed lines : under irradiation. Full lines : « in the dark ».

figure 2 we plot $\tau v$ s. $\delta$ for different initial conditions, with and without irradiation. The general behaviour of the curves is typical of the relaxation behaviour in the glassy state [10] (distribution of relaxation times, non linear behaviour). The effect of the gamma radiation consists of a shift of the order of one decade in the time scale, without qualitative changes in the shapes of the curves.

The differential activation energy

$$
W=\frac{\mathrm{d}\left[\ln \left(\tau_{0}\right)\right]}{\mathrm{d}\left(T^{-1}\right)} ; \quad \tau_{0}=\lim _{\delta \rightarrow 0} \tau(\delta)
$$

calculated from these experiments are equal to $4 \times 10^{4} \mathrm{~K}$ in the dark and $3 \times 10^{4} \mathrm{~K}$ under irradiation. This indicate that the $\gamma$-ray effect must be relatively more important at lower temperatures.

Therefore, by irradiating glassy samples at temperatures well below $T_{g}$, it should be possible to investigate the nature of the equilibrium states in the previously experimentally forbidden region near $T_{0}$.

\section{References}

[1] Vogel, H., Phys. Z. 22 (1921) 645.

[2] Fulcher, G. S., J. Am. Ceram. Soc. 8 (1925) 339.

[3] Cohen, M. H. and Turnbull, D., J. Chem. Phys. 31 (1959) 1764.

[4] Adam, G. and Gibbs, J. M., J. Chem. Phys. 43 (1965) 139.

[5] Angell, C. A. and Rao, K. J., J. Chem. Phys. 57 (1972) 470.

[6] Anderson, P. W., Ecole d'Eté, Les Houches (1978).
[7] JofFrin, J., Ecole d'Eté, Les Houches (1978).

[8] Calemczuk, R. and Bonjour, E., J. Non-Cryst. Solids 43 (1981) 427.

[9] Rapport annuel SBT/CENG (1981) 69.

[10] Kovacks, A. J., Fortschr. Hochpolym. Forsch. 3 (1963) 394.

[11] Calemczuk, R. C., Thèse, Université de Grenoble (1977). 